\title{
The Study of Vietnamese Bonechar Synthesis and its Applications in Removal Organic Color
}

\author{
Vo Thanh Cong ${ }^{1 *}$, Tran Tan Nhat ${ }^{2}$, Do Quy Diem ${ }^{1}$, Nguyen Van Son ${ }^{1}$ \\ ${ }^{1}$ Faculty of Chemical Engineering, Industrial University of Ho Chi Minh City \\ Viet Nam \\ ${ }^{2}$ Faculty of Chemical Egineering, Ho Chi Minh City University of Food Industry \\ Viet Nam \\ *Corresponding author's email: vothanhcong [AT\} iuh.edu.vn
}

\begin{abstract}
Biochar was synthesized from two material sources such as animal waste or plant waste. In this work, biochar was synthesized going from bovine bone waste at Vietnam country, called as Vietnamese bone char (VNBC). Many steps of process to VNBC synthesis, and its surface characteristics were investigated, respectively. The applications of VNBC being as adsorbents were examined then. The results of synthesis process were obtained the $V N B C$ product sample with optimal condition to be at temperature of $650^{\circ} \mathrm{C}$, corresponding to 120 minutes. The analysis on surface properties of VNBC indicated that the specific surface area were $120.315 \mathrm{~m}^{2} / \mathrm{g}$, with pore diameter as 87.48 A measured by BJH (Barrett, Joyner and Halenda) method. The surface morphology with the particle size measured by SEM (Scanning Electronic Spectroscopy) method was $70 \mathrm{~nm}$. The composition compounds of VNBC contained calcium carbonate-hydroxyl apatite with the formula was $\mathrm{Ca}_{10}\left(\mathrm{PO}_{4}\right)_{5.65}\left(\mathrm{CO}_{3}\right)_{0.64}(\mathrm{OH})_{3.45}$ measured by FT-IR (Fourier Transform Infrared Spectroscopy) and XRD (X-Ray Diffraction Spectroscopy) methods, respectively. In application, VNBC uses at optimal condition as an adsorbent to remove the organic color solutions for instance $\mathrm{KMnO}_{4}$ and methylene blue (MB) were considered. The results of VNBC adsorbent to remove the colored solutions measured by UV/VIS (Ultraviolet Visible spectroscopy) method are obtained with adsorption capacity of $\mathrm{KMnO}_{4}$ as from 33.51 to $46.22 \mathrm{mg}$ color/g BC, and MB from 12.1 to $15.04 \mathrm{mg}$ color/g $B C$, respectively. These results shown that VNBC were able to use making a potential adsorbent in the treatment of wastewater contained organic color in industry.
\end{abstract}

Keywords--- Bovine bone waste, VNBC synthesis, Adsorbent, Organic color solution

\section{INTRODUCTION}

The use of meat or fish making food for human has been disseminated in all over the world. This means that the slaughterhouses have to produce an enormous amount of bovine or fish bones. This growing amount of bone residue among other waste materials from meat and fish processing industries considered such as one of the pollutants to environmental challenges that the food industry is facing today. In detail data after slaughtering, one animal is able to produce about 18 weight $\%$ bone residues of its total live weight, which considered as slaughterhouse waste source[1-3]. Further, the chemical compositions from bovine bones were consisted with a compound both organic (30\%) and inorganic (70\%) in which proper mechanical properties of bones as stiffness depended on their mineral parts. The model compound into mineral phase of bones is a biological apatite called as nonstoichiometric hydroxyapatite $[4,5]$. This nonstoichiometric hydroxyapatite was used in enamel and dentine with the $\mathrm{Ca} / \mathrm{P}$ molar ratio exceeds 1.67 . Based on its chemical and structural minerals, bovine bone is not only a biocompatible, osteoconductive, non-toxic, noninflammatory and nonimmunogenic agent, but also bioactive to apply greatly in biochemistry[1, 5].

In previous bone residues, inefficient management of these bones are creating an effective variety of problems to the endanger public health and the environment in general. When bones are waste in land, this bone wastes created a pollution of surface and underground waters and air quality $[6,7]$. As a result, it is caused the affective health of residents living within the vicinity of the abattoirs, destroyed water bodies making affectively to fish yield thus [8, 9]. In addition, bone wastes are also ideal breeding grounds for disease causing organisms (pathogens) to development. It is usually disposed by burning since treatment, was effected thus to which further pollutes the air and endanger human lives.

Adsorption is a phenomena to known that as the consist in the transfer of an adsorbate from a gas or liquid phase to an adsorbent, in which it existed a bonding through intermolecular forces. In adsorption, the quantity of adsorbate in a surface area unit is small. Because of this, normally porous adsorbents with a great internal surface area are selected. On the other hand, it has two types of adsorption phenomena that can be know such as physical and chemical. Physical adsorption, easily reversible, is the result of Van der Waals intermolecular forces (physical interaction) between adsorbent and adsorbed substance (adsorbate). This interactions is weak, thus the energy when the molecule physisorbed is about the same order of magnitude as the condensation enthalpy[10-12]. Whereas, chemical adsorption is the result of the chemical interaction 
between the adsorbent and the adsorbate to form the chemical bonds. Hereafter, the chemical bond force is able to vary so that chemical compounds cannot be formed in the usual way. However, the adsorption forces of chemisorption is normally a lot higher than of physisorption. During chemisorption, the heat is always released, and as an exothermic process, which commonly is similar to a chemical reaction heat. In addition, it is the same substance that at low temperatures experiences essentially for physical adsorption, sometimes exhibited for chemical adsorption at higher temperatures, and can be both processes simultaneously[13-15].

The adsorption process has a widely application in environmental treatment. Specially, liquid-solid adsorption systems are based on the ability of certain solids as adsorbents to preferentially concentrate specific substances (adsorbates) from solutions onto their surfaces. This rule can be used for the removal of pollutants, such as metal ions and colored organics from wastewater. To adsorbents producing used for adsorption process, a number of low-cost agricultural wastes such as mud tire rubber, and ash are investigated. Other potential minerals and materials for instance bentonite and bone char as potential adsorbents have been tested also, respectively. Many previous studies have been reported during the last ten years to find the low-cost, and efficient adsorbents for the removal of metal ions or color compounds in wastewater [16-20].

Actually, bone char has been successfully synthesized and used for fluoride removal in Tanzania and Thailand [21, 22]. The effectiveness of bone char as an adsorbent has been performed using batch experiments with contained heavy metal ions and color solutions under different conditions, for example, variable $\mathrm{pH}$, temperature, chemical and thermal activation, adsorbent dosage $[17, \mathbf{1 8}, \mathbf{2 3}$. However, the synthesis process of bone char and its application in wastewater treatment containing metal ions and color solutions at Vietnam (VNBC) are still new research.

Bone char is a material obtained by carbonizing animal bones. It is consisted mainly compound of hydroxiapatite and carbonate with its zero charge point between $\mathrm{pH} 8$ and 9. Bone char has been used for thousands of years in many fields such as fertilizer, pigment, cosmetics, and varnish. Recent studies have used bone char to adsorb radioisotopes of antimony and europium ions from radioactive wastes. Researchers claimed that sorption is due to cation exchange of metal ions onto hydroxyapatite $[14,16,22-25]$. Therefore, the goal of this study is to find the process of VNBC synthesis from bovine bone waste. Simultaneously, VNBC product then is measured by analysis methods to determine the surface properties. Finally, we try to apply VNBC product as an adsorbent to remove the organic colors in solution. In the detail this works, the samples of bovine bone waste are treated and calcinated then in conditional without oxygen at different temperature and time to find the optimal condition burning. The optimal VNBC sample, then are chosen and measured surface properties by analysis methods. The effects of conditional temperature and time to adsorption capacity on VNBC are also investigated.

\section{MATERIAL AND METHODS}

Many samples of the bovine bone wastes collected from cow slaughterhouse, and experiments to VNBC synthesis are performed at the Faculty of chemical engineering, Industrial University of Ho Chi Minh City of Vietnam. In all experiments and measurements are that the first step, we fixed each time (time constant) to calcine the bovine bond samples to VNBC products with the changed temperature from $500-800{ }^{\circ} \mathrm{C}$, and trying to then adsorption capacity of VNBC products with color solutions such as $\mathrm{KMnO}_{4}$ and $\mathrm{MB}$. Hereafter, the highest adsorption capacity product is found to correspond with optimal temperature burning. In second step, by repeating similar experiments in the first step, temperature (temperature constant) is fixed but to find optimal time burning. Finally, VNBC product in synthesis process having an optimal temperature and time burnings were found, and measured the surface characteristic by analysis methods.

In trying to color adsorption on VNBC products, the concentrated color solutions after adsorption was analyzed by UVVIS spectrophotometer. Here, this method consists in forming a $\mathrm{KMnO}_{4}$ color complex and methylene color complex which are measured with photometric measurement of absorbance at a wavelength of $550 \mathrm{~nm}$ and $650 \mathrm{~nm}$, respectively. The adsorption capacity $\left(\mathrm{C}_{\mathrm{ads}}\right)$ is calculated as $(1)$ follows:

$$
\mathrm{C}_{\mathrm{ads}}=\frac{\left(\mathrm{C}_{0 \mathrm{i}}-\mathrm{C}_{\mathrm{ei}}\right) \times \mathrm{V}}{\mathrm{m}}
$$

In which, $\mathrm{C}_{0 \mathrm{i}}$ and $\mathrm{C}_{\mathrm{ei}}$ are initial and equilibrium concentrations of colored $\mathrm{KMnO}_{4}$ or colored $\mathrm{MB}$ solution, respectively. $\mathrm{V}$ is the volume of adsorption solution (L), and $\mathrm{M}$ as the weight of biochar $(\mathrm{g})$.

To determine the surface properties of optimal VNBC product such as compound components and phase composition are analyzed by X-ray Diffraction (XRD) method with graphite monochromator using Cu-K $\alpha$ of 1.54, combined with FT-IR analysis spectrophotometer in the range of middle infrared from 400 to $4000 \mathrm{~cm}^{-1}$. In addition, the effect of calcination temperature on the microstructure of optimal VNBC sample is analyzed also using scanning electron microscope (SEM). The calculations of adsorption capacity analysis methods are used in this work to be in line with previous experiments[26, 27]. Many results of synthesis process and analysis are performed respectively in following below,

\subsection{The process to VNBC synthesis}

\section{RESULTS AND DISCUSSION}

The samples of bovine bone waste are collected from cow slaughterhouse, washed with hot water at temperature (T) from 50 to $60{ }^{\circ} \mathrm{C}$, done then the fat clean with weak soap solution. The samples are washed continuously with hot water at 50 - 
$60{ }^{\circ} \mathrm{C}$, and dried at $105^{\circ} \mathrm{C}$. Finishing wash, bovine bone wastes are grinded the small pieces before calcinating into furnace to $\mathrm{VNBC}$ product. The process of $\mathrm{BC}$ synthesis is in following:

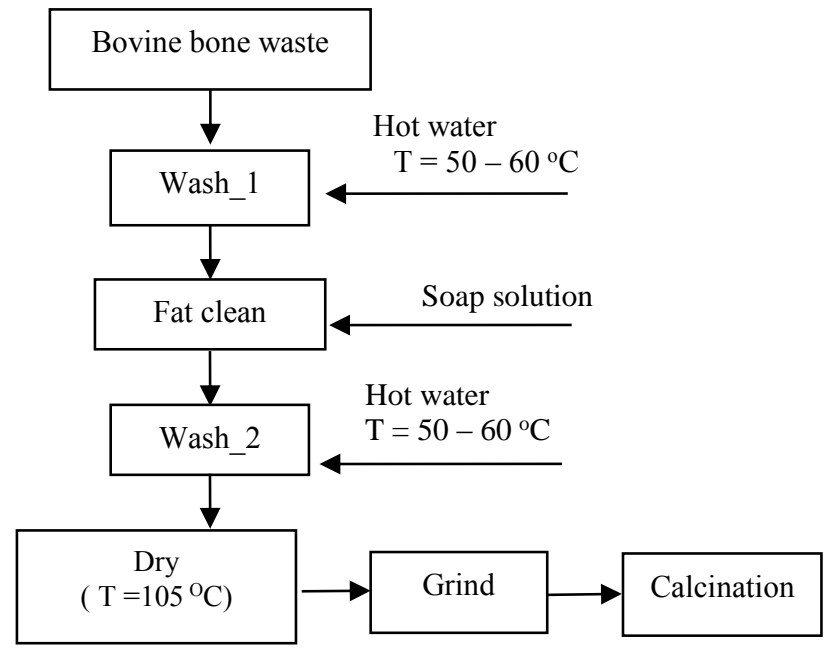

Figure 1: VNBC synthesis process

The most important step of synthesis is bone calcinated into furnace at the condition of without oxygen. The principle and structure of pyrolysis furnace with laboratory model in charring of bone is designed similarly to previous study[28]. By doing this, the performance of synthesis steps from bovine bone waste to VNBC product was obtained experiments at laboratory as shown in Figure 2.

(a)

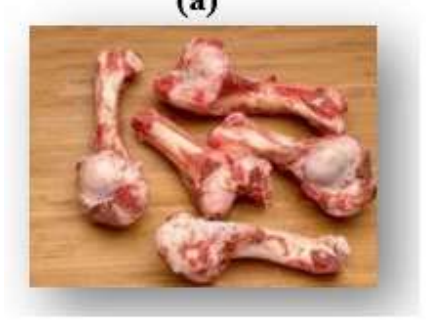

(b)

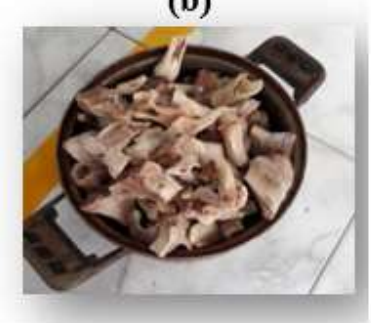

(c)

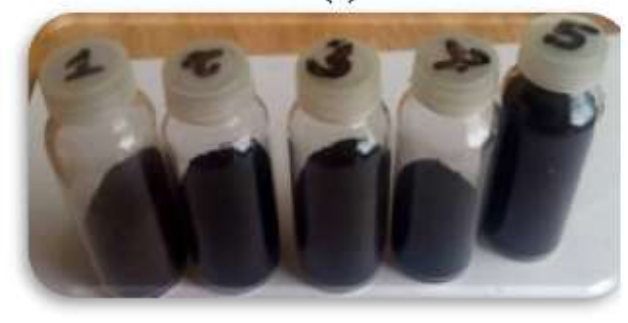

Figure 2: The images of VNBC synthesis process in laboratory. It is denoted that Figure (a) as bovine bones collected from cow slaughterhouse, Figure (b) as bovine bones cleaned, and Figure (c) as bovine bones synthesized to VNBC, respectively.

\subsection{The experiments on burned temperature effects to}

\section{+ BC synthesis}

In this works, we do the performance that, each a bovine bone samples (BBs) after cleaning is weighed with initial $\mathrm{m}_{1} \mathrm{mass}$ (in gram, g), and then burned at conditional without oxygen at 60 minutes, where it is changed the temperature burning $\left(\mathrm{T}_{\mathrm{b}}\right)$ from 400 to $800{ }^{\circ} \mathrm{C}$. After burning, VNBC product is weighed to determine the $\mathrm{m}_{2}$ mass $(\mathrm{g})$ in each BBs. The results of burned temperature effect and recover efficiency as the ratio of $\mathrm{m}_{2}$ divided $\mathrm{m}_{1}$, namely $\mathrm{E}$ (in percentage, \%) of VNBC products at different temperature are obtained and listed in Table 1, respectively.

Table 1: The effects of burning temperature to VNBC synthesis. 


\begin{tabular}{|lllll|}
\hline \hline BBs & & & & \\
Sample & $\mathrm{T}_{\mathrm{b}}$ & $\mathrm{m}_{1}$ & $\mathrm{~m}_{2}$ & $\mathrm{E}$ \\
\hline \hline $400-60$ & & & & \\
$450-60$ & 400 & 86.84 & 80.05 & 92.18 \\
$500-60$ & 450 & 105.5 & 85.36 & 80.91 \\
$550-60$ & 500 & 98.32 & 87.35 & 88.84 \\
$600-60$ & 550 & 100.68 & 87.77 & 87.18 \\
$650-60$ & 600 & 104.32 & 88.93 & 85.25 \\
$700-60$ & 650 & 93.1 & 81.32 & 87.35 \\
$750-60$ & 700 & 90.01 & 77.93 & 86.58 \\
$800-60$ & 750 & 96.64 & 84.22 & 87.15 \\
\hline \hline
\end{tabular}

We observed in Table 1 that $\mathrm{E}$ is about $80-90 \%$. This means that uses of BBs to VNBC product have a good efficiently economic in synthesis process. In addition, the VNBC products are charred bone does not add color, taste or smell to the water which it is in line with bone char products in previous experiments[15, 22, 23, 28, 29]. This is able to help us having a confident method in VNBC synthesis, also potential applications of product in next time research.

\subsection{Adsorption capacity on $\mathrm{VNBC}$ with colored $\mathrm{KMnO}_{4}$ and $\mathrm{MB}$ solutions to find optimal temperature burning}

The first in all of experiments, the VNBC is grinded to particle size as $3 \mathrm{~mm}$. Continously, in each experiment, a mixing $3 \mathrm{~g}$ of VNBC sample $\left(\mathrm{m}_{0}\right)$ is added with $50 \mathrm{ml}$ of $\mathrm{KMnO}_{4} 0.01 \mathrm{~N}\left(\mathrm{~V}_{\mathrm{KMnO}}\right)$ or $0.01 \% \mathrm{MB}\left(\mathrm{V}_{\text {methylene }}\right)$ solution, and shaken then at 60 minute with 250 revs per minute. After that time, samples are measured by volume analysis standard method which the results presented in Table S1 and Table S2 (supplemental material), respectively.

It is an observation from Table $\mathrm{S} 1$ and Table $\mathrm{S} 2$, all of VNBC samples are having an adsorption capacity both $\mathrm{KMnO}_{4}$ and $\mathrm{MB}$. However, the adsorption capacity of each VNBC sample is different at interval temperature. By doing this, we have rejected the samples which it is at temperature burning from $400{ }^{\circ} \mathrm{C}$ to $550{ }^{\circ} \mathrm{C}$ for adsorption both $\mathrm{KMnO}_{4}$ and $\mathrm{MB}$. Continuously, the repeating performance of conditional experiments for temperature burning from $600{ }^{\circ} \mathrm{C}$ to $800{ }^{\circ} \mathrm{C}$, VNBC samples are analyzed by UV/VIS method to determine the adsorption capacity in which all results given both $\mathrm{KMnO}_{4}$ and MB, shown in Figure 3.

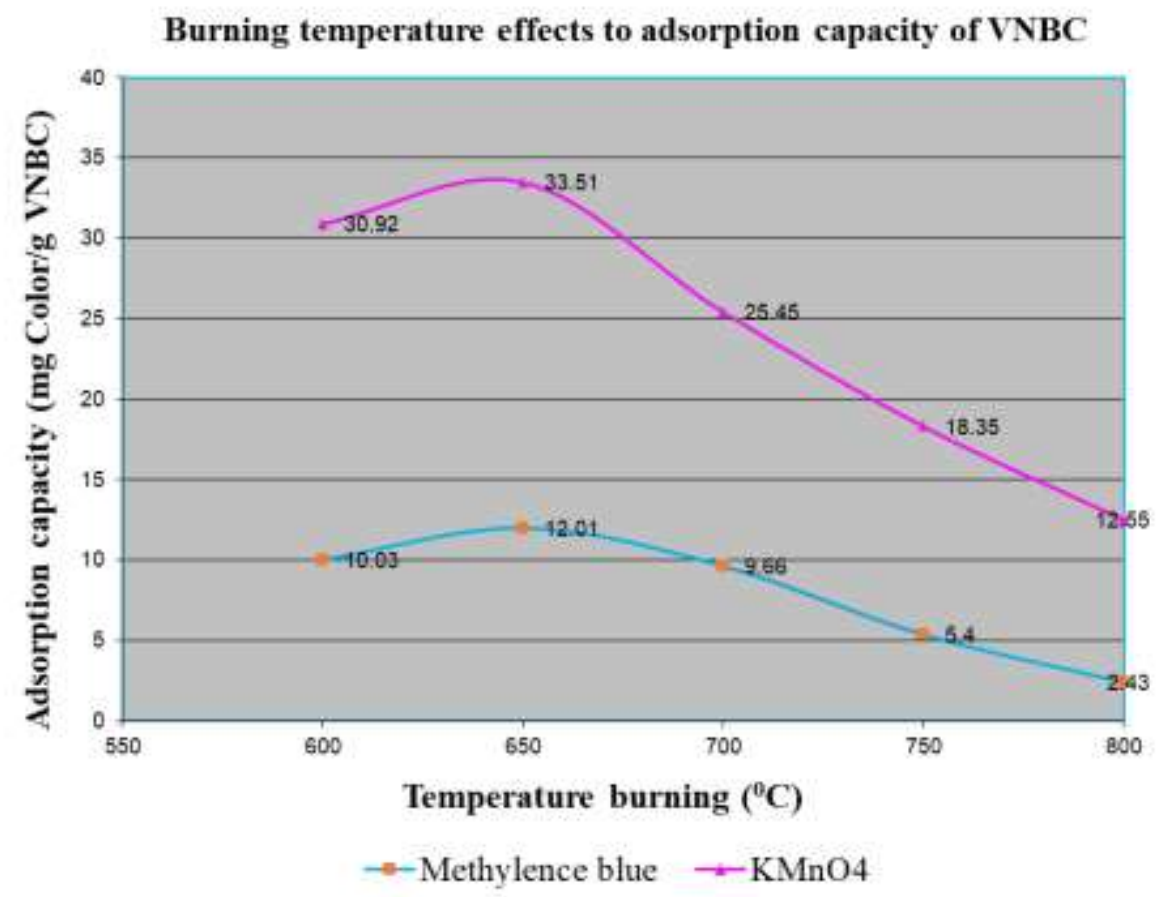

Figure 4: Chart of time changes effected to adsorption capacity on bonechar

We observed the results of chart in Figure 3 that the adsorption capacity of VNBC samples at temperature burning from $800{ }^{\circ} \mathrm{C}$ to $650{ }^{\circ} \mathrm{C}$ are increased, and decreased then from $650{ }^{\circ} \mathrm{C}$ to $600{ }^{\circ} \mathrm{C}$ for both $\mathrm{KMnO}_{4}$ and $\mathrm{MB}$ adsorptions. Specially, the adsorption capacity of VNBC sample is highest with $\mathrm{KMnO}_{4}$ to be $33.51 \mathrm{~g}$ color/ $\mathrm{g} \mathrm{VNBC}$, and MB as $12.01 \mathrm{~g}$ color/g 
VNBC at $650{ }^{\circ} \mathrm{C}$. In addition, different adsorption capacity will be depended on colored concentration and type colored agent into solution. This result is to say that VNBC synthesized at optimal temperature burning as $650{ }^{\circ} \mathrm{C}$.

\subsection{Experiments on burned time effects to $\mathrm{BC}$ synthesis}

Repeating all experiments are the same with burned temperature effects above (part-3.2) to VNBC synthesis. However, in these experiments, we fixed the temperature burning (temperature constant) at $650{ }^{\circ} \mathrm{C}$ in each a bovine bone sample (BBs), in which BBs is changed the conditional time burning from 30 minutes to 210 minutes $\left(\tau_{\mathrm{b}}\right)$. The results of burned time effect and recover efficiency of VNBC products at different time are obtained and presented in Table 2, respectively.

\begin{tabular}{lllll}
\multicolumn{5}{l}{ Table 2: The effects of time burning to VNBC synthesis. } \\
\hline $\begin{array}{l}\text { BBs } \\
\text { Sample }\end{array}$ & $\tau_{\mathbf{b}}$ & $\mathrm{m} 1$ & $\mathbf{m} \mathbf{2}$ & $\mathbf{E}$ \\
\hline $650-30$ & 30 & 95,50 & 83,74 & 87,69 \\
$650-60$ & 60 & 90,43 & 78,57 & 86,88 \\
$650-90$ & 90 & 120,27 & 99,86 & 83,03 \\
$650-120$ & 120 & 81,00 & 71,31 & 88,04 \\
$650-150$ & 150 & 110,34 & 93,15 & 84,42 \\
$650-180$ & 180 & 98,24 & 86,84 & 88,40 \\
$650-210$ & 210 & 103,07 & 87,73 & 85,12 \\
\hline
\end{tabular}

3.5. Adsorption capacity on $\mathrm{VNBC}$ with colored $\mathrm{KMnO}_{4}$ and $\mathrm{MB}$ solutions to find optimal time burning In this performance, we also repeat all the same experiments with adsorption capacity on $\mathrm{VNBC}$ with colored $\mathrm{KMnO}_{4}$ and MB solutions above (part-3.3). However, in this experiment, the conentration of $\mathrm{KMnO}_{4}$ solution as $0.001 \mathrm{~N}$ or $0.001 \%$ of MB solution are used to try adsorption capacity. After that time, samples are measured by UV/VIS method to determine the optimal adsorption capacity, corresponding with optimal time burning. The resulted adsorption capacity is given with $\mathrm{KMnO}_{4}$ and $\mathrm{MB}$, listed in Table S1 and Table S2 (supplemental material), respectively. Then, to be more clearly, a plotted the relation between time burning and capacity on chart together, which it is given results in Figure 4.

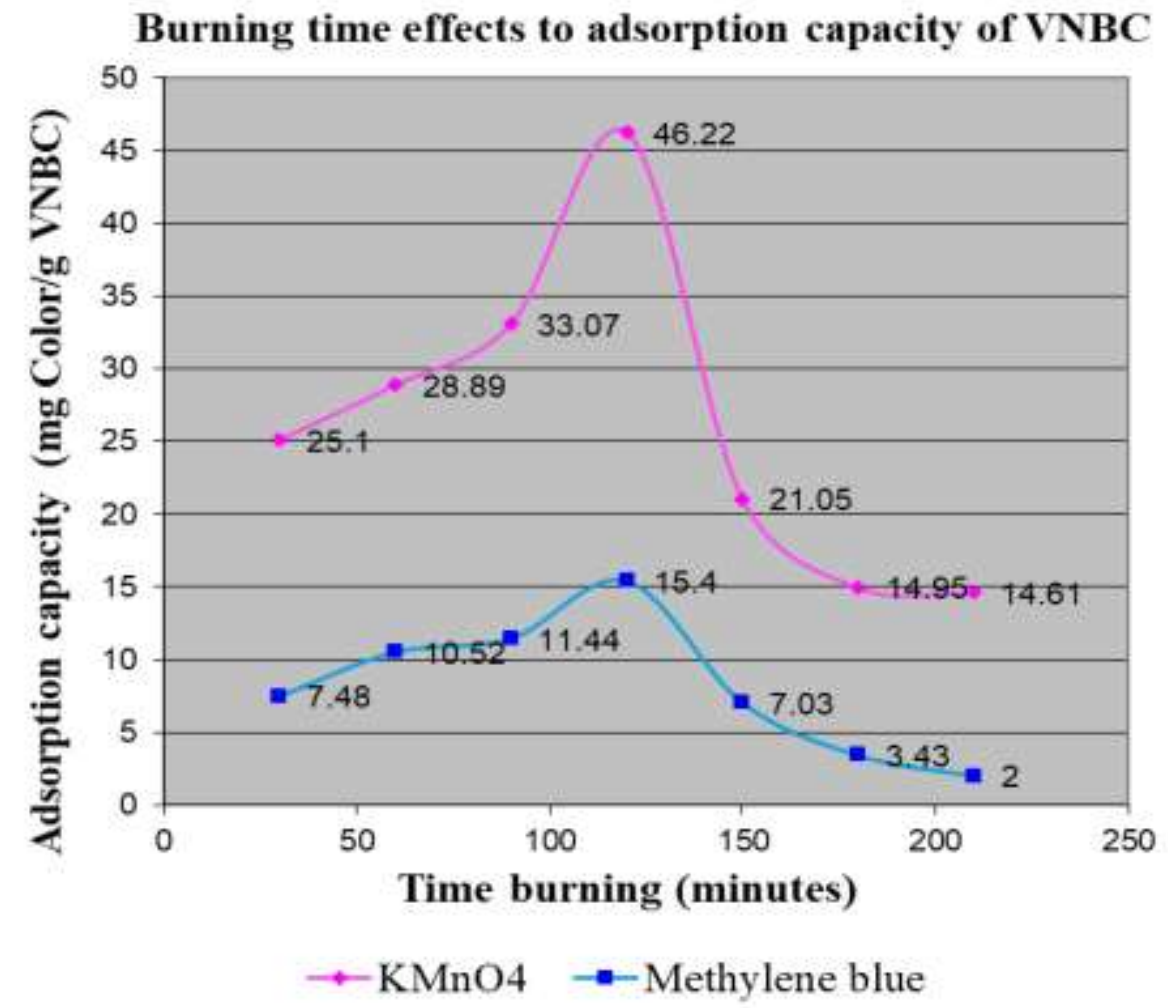

Figure 4: Chart of time changes effected to adsorption capacity on bonechar

It is observed the results of chart in Figure 4 that adsorption capacity of VNBC samples at time burning from 30 to 120 minutes are increased, and decreased then from 120 to 201 minute with both $\mathrm{KMnO}_{4}$ and $\mathrm{MB}$ adsorptions. Specially, the 
adsorption capacity of VNBC sample is highest with $\mathrm{KMnO}_{4}$ to be $46.22 \mathrm{~g}$ color/ $\mathrm{g}$ VNBC, and MB as $15.4 \mathrm{~g}$ color/g VNBC at 120 minutes. This means that VNBC synthesized at optimal time burning is at 120 minutes.

From experiments about the optimum of temperature and time burning, it is followed us to conclude that the sample having temperature burning at $650{ }^{\circ} \mathrm{C}$ corresponding with time burning of 120 minutes is an optimal sample in VNBC synthesis process. This conclusion is in line with previous study[27, 30] to which we can be confident that the VNBC synthesis process is a successful to extent application in industrial product. Hereafter, the optimal VNBC sample is analyzed to determine the surface properties by analysis, in following.

\subsection{The resulted characteristic surface of optimal VNBC}

\section{BJH analysis}

Generally, BJH [31] described a technique to estimate the volume and area of porous adsorbents available to molecules of various sizes. This analyzed techniques were based on the combination between theoretical BET[32] and computational simulation to determine the pore diameter and surface are of adsorbents exhibiting a wide range of pore sizes, and described appears to be applicable to porous solids of any nature. By this method thus, the optimal VNBC sample is analyzed by BJH method to what measured results, presenting in Figure 5.

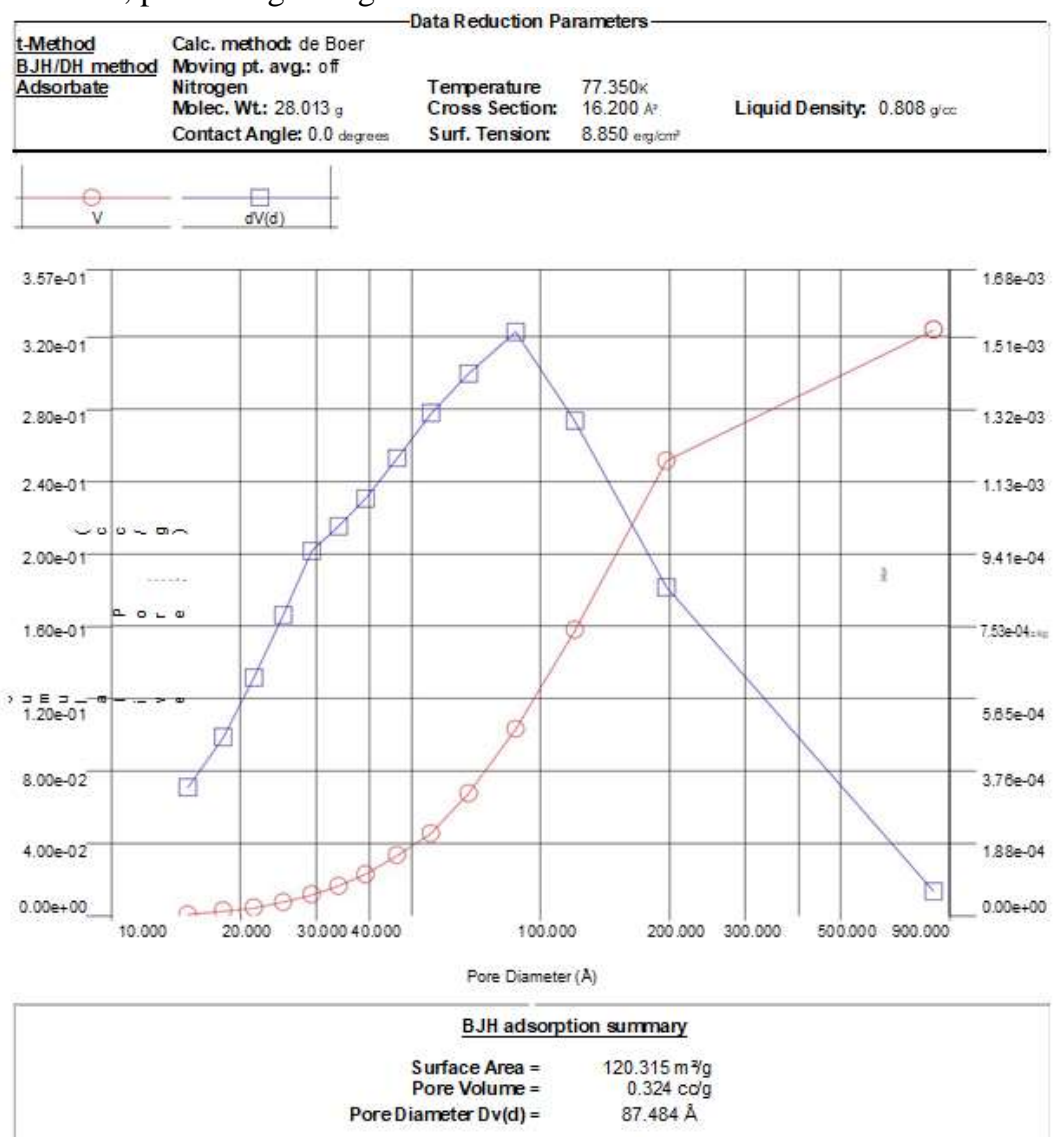

Figure 5: Chart of pore diameter and specific surface area of optimal VNBC sample

The measured results is observed from Figure 5 that optimal VNBC sample has a specific surface area to be $120.315 \mathrm{~m}^{2} / \mathrm{g}$ with pore diameter of $87.48 \AA(8.75 \mathrm{~nm})$, this is able to say that VNBC such as mesoporous material has a good adsorption capacity to which it has many potential applications in industry. The resulted BJH

analysis of specific surface area in present work is varying interval with BET analysis in previous invesstigation[27], this may be due to the differnce of method or different animal bone which effect to synthesis process.

\section{SEM analysis}

SEM examinations is confirmed that VNBC product at optimal condition of temperature and time to demonstrate a diversified propensity for crystal agglomeration on the surface. In this work, the surface morphology and crystal size of optimal VNBC sample is measured using SEM method, shown in Figures 6. 
(a)

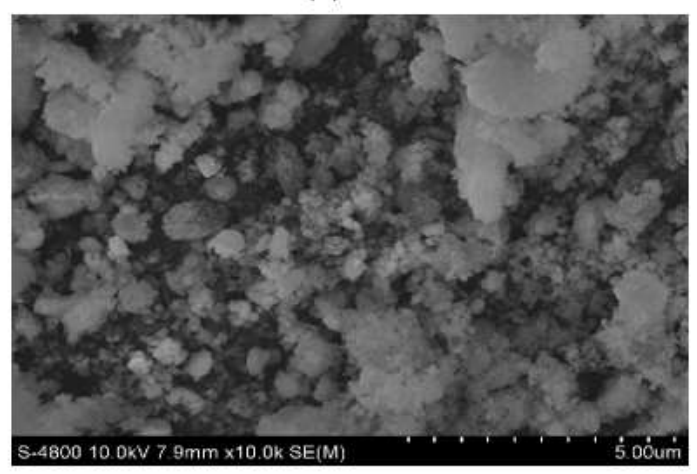

(b)

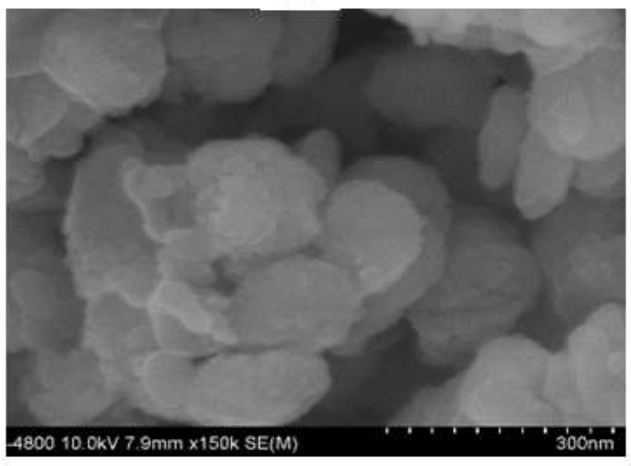

Figure 6: Resulted SEM images of optimal VNBC sample. In which, scale of figure 6(a) and 6(b) are noted as SEM images at $5 \mu \mathrm{m}$ and $300 \mathrm{~nm}$, respectively.

It is an observation at Figure 6(a) that the microcrystal of VNBC sample contributed to be uniform and small particle size. To be more clearly, a scale of VNBC at $300 \mathrm{~nm}$ is taken with image in Figure 6(b) to give a crystalline size is from 200 $\mathrm{nm}$ to $250 \mathrm{~nm}$. Resulted SEM image in this study is in line with previous experiment[27], this means that VNBC synthesis method has a suitable.

\section{FTIR analysis}

The importance of FTIR analysis is to identify characteristic functional groups on the surface of the adsorbent such as VNBC in present work. The resulted FTIR spectra is measured, and shown in Figure 7.

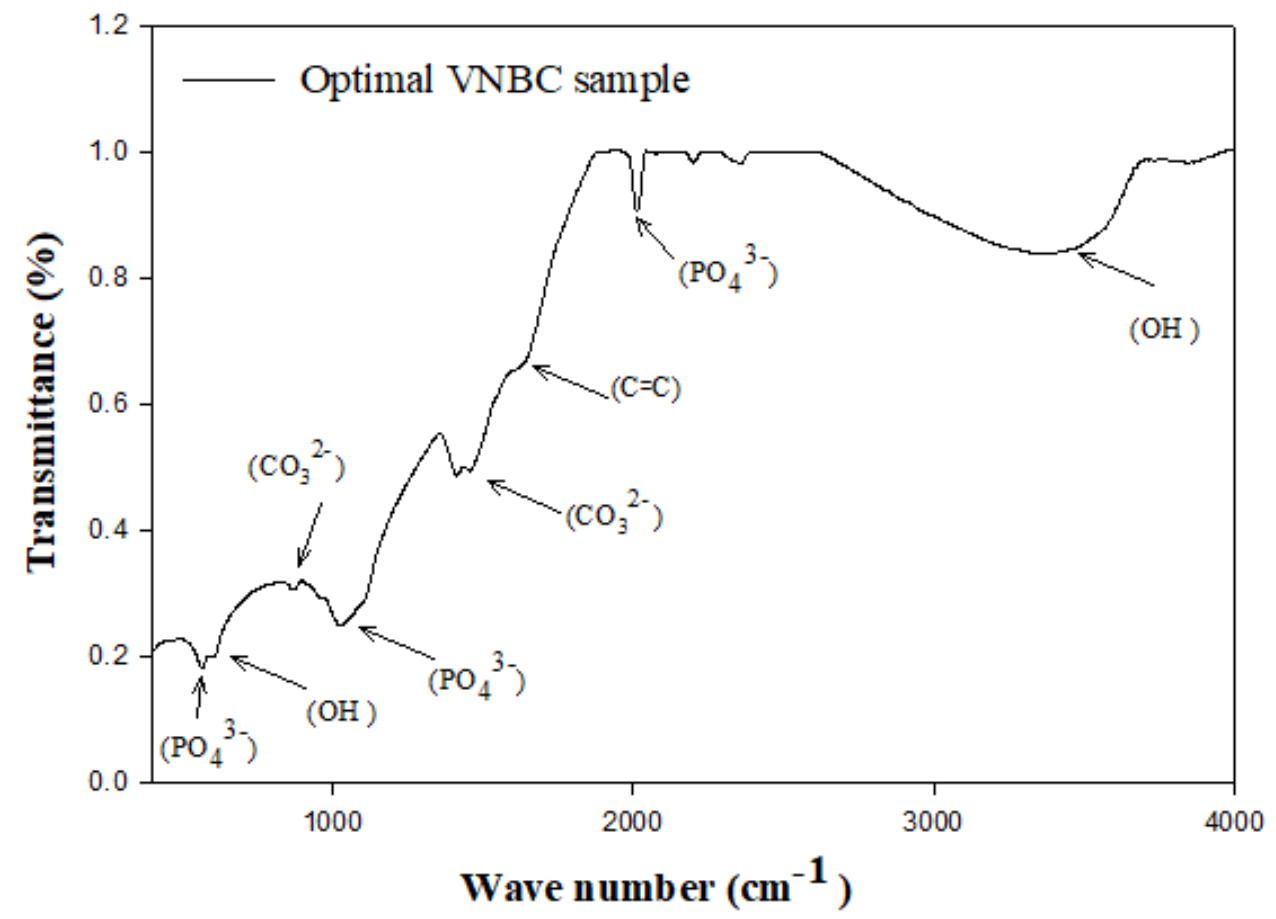

Figure 7: FTIR results of bovine bone after calcined at optimal condition

FT-IR analysis of bone char products from animal bones in previous experiment $[27,30,33]$ have been reported that, in transmittance mode, shown the presence of carbonate group at around 1410-1450 $\mathrm{cm}^{-1}$ and $873 \mathrm{~cm}^{-1}$, carbon group at C-C $\left(1200 \mathrm{~cm}^{-1}\right), \mathrm{C}=\mathrm{C}\left(1650 \mathrm{~cm}^{-1}\right)$, and $\mathrm{C} \equiv \mathrm{C}\left(2150 \mathrm{~cm}^{-1}\right)$, with hydroxide group at around $3500-3200 \mathrm{~cm}^{-1}$, respectively. For phosphate group at 1030-1090 $\mathrm{cm}^{-1}$ and $1950-2200 \mathrm{~cm}^{-1}, 962 \mathrm{~cm}-1$ and $560 \mathrm{~cm}^{-1}$. Herein, previous observations at figure 7 , the bands corresponding to the vibrations of $\mathrm{C}-\mathrm{H}$ and $\mathrm{C}-\mathrm{C}$ bonds of organic compounds is absent which this confirmed that a total organic matter was removed after the synthesis process. It is only weak band of $\mathrm{C}=\mathrm{C}$ bond at $1652 \mathrm{~cm}^{-1}$ which we predicted that the VNBC sample existing with carbon black composition. Continuously, the presence of characteristic bands of phosphate group $\left(\mathrm{PO}_{4}{ }^{3-}\right)$ is resulted that the sharp peaks existing the wave number of $572 \mathrm{~cm}^{-1}$ assigned to bending mode of phosphate and $625 \mathrm{~cm}^{-1}$ for the presence of hydroxyl group $(\mathrm{OH})$. The most intensive bands of $1030 \mathrm{~cm}^{-1}$ and

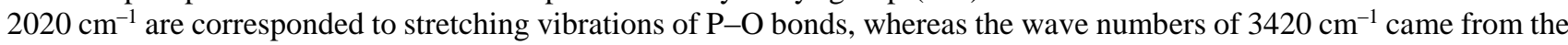
symmetric stretching vibration of $\mathrm{H}-\mathrm{O}$ bonds. In addition, the low-intensity bands at 1420 and $873 \mathrm{~cm}^{-1}$ is observed for sample corresponding to the vibration mode of carbonate group $\left(\mathrm{CO}_{3}^{-2}\right)$. These follow us to conclude that the optimal VNBC sample is contained the structure of carbonate hydroxyl apatite compounds. 


\section{XRD analysis}

To sight more lights, phase composition of optimal VNBC sample is measured using XRD analysis. The analysis results of VNBC sample at optimal condition presented in Figure 8.

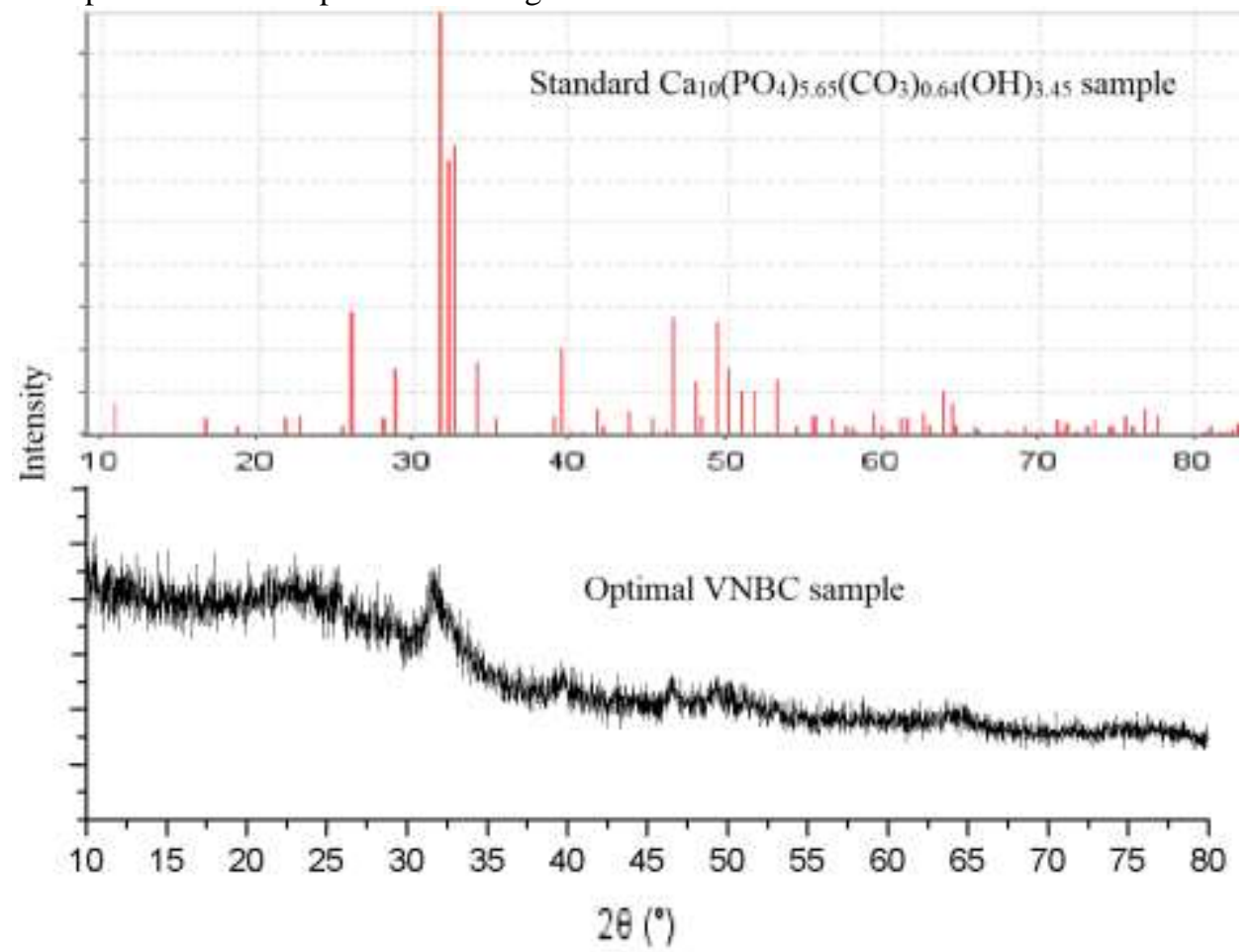

Figure 8: The resulted spectrum of optimal VNBC sample measured by XRD

It is an observation XRD spectrum in Figure 8 that, the peaks of VNBC sample (solid line) is overlapped with the peaks of

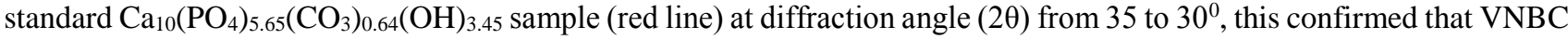
sample existing the composition of $\mathrm{Ca}_{10}\left(\mathrm{PO}_{4}\right)_{5.65}\left(\mathrm{CO}_{3}\right)_{0.64}(\mathrm{OH})_{3.45}$ compound (calcium carbonate-hydroxyl apatite). The XRD analysis in this work is an agreement with previous studied $[15,27,29,30]$ to which confirm again that the method of VNBC synthesis process is successful.

\section{CONCLUSION}

From the investigations, we draw some conclusions in following,

(1) The steps of process to VNBC synthesis, many samples of bovine bone waste are calcinated in laboratory which VNBC sample found at optimal condition of $650{ }^{\circ} \mathrm{C}$, corresponding with 120 minutes.

(2) Organic color treatments in waste water are essential to avoid the water pollution in industry and life, the use of VNBC product as an adsorbent is examined with this purpose. The results of colored solution adsorption on optimal VNBC sample is obtained with highest capacity adsorption of $\mathrm{KMnO}_{4}$ to be from 33.51 to $46,22 \mathrm{mg}$ color/g VNBC, and MB from 12.1 to 15,04 mg color/g VNBC, respectively. These results are first step to confirm that applied capacity of VNBC product to treat the waste water contained colored agents in industry has a potential and effective application.

(3) Many analyses on optimal VNBC sample were measured to determine the surface characteristics. In these analysis methods, SEM can be helpful to describe the morphology of VNBC at nanoscale level with a crystalline size of from 200 to $250 \mathrm{~nm}$. FTIR and XRD technique given us to find out that crystalline nature of VNBC, existing the calcium metal is combined with $\mathrm{PO}_{4}^{-3}, \mathrm{CO}_{3}{ }^{2-}$, and $\mathrm{OH}^{-}$groups, to which structural crystal was $\mathrm{Ca}_{10}\left(\mathrm{PO}_{4}\right)_{5.65}\left(\mathrm{CO}_{3}\right)_{0.64}(\mathrm{OH})_{3.45}$ compound (calcium carboxyl-apatite). Furthermore, the $\mathrm{BJH}$ technique can be used to distinguish the types of pore material and adsorption capacity of adsorbents. Hence, the resulted specific surface area of $120.315 \mathrm{~m}^{2} / \mathrm{g}$ with pore diameter of $87.48 \AA(8.75 \mathrm{~nm})$ measured to what VNBC sample in this study is a good adsorbent and as a mesoporous material having potential applications in industry.

This study is the first step to design successfully the process of VNBC synthesis, also apply it to be an adsorbent in colored solution treatments at laboratory level. Many other applications and kinetic model of VNBC will be studied continuously in next research.

\section{ACKNOWLEDGEMENT}

We thank to the Faculty of chemical engineering of industrial University of Ho Chi Minh to where support this research financially, experimental laboratory, and other facilities. 
Supplementary material showing at Table S1 and Table S2 give the effects of temperature burning to adsorption capacity of $\mathrm{VNBC}$ with $\mathrm{KMnO}_{4}$ and $\mathrm{MB}$. Whereas, Table $\mathrm{S} 3$ and Table S4 was presented as effects of time burning to adsorption capacity of $\mathrm{VNBC}$ with $\mathrm{KMnO}_{4}$ and $\mathrm{MB}$, respectively.

Table S1. Effects of temperature burning to adsorption capacity of VNBC with $\mathrm{KMnO}_{4}$

\begin{tabular}{|c|c|c|c|}
\hline $\begin{array}{l}\text { VNBC } \\
\text { sample }\end{array}$ & $\mathrm{m}_{\mathrm{O}}$ & $\mathrm{V}_{\mathrm{KMnO} 4}$ & $\begin{array}{c}\text { Adsorption capacity } \\
\left(\mathrm{mg} \mathrm{KMnO}_{4} / \mathrm{g} \text { VNBC) }\right.\end{array}$ \\
\hline $400-60$ & 3 & 50 & \multirow{4}{*}{$<5,27$} \\
\hline $450-60$ & 3 & 50 & \\
\hline $500-60$ & 3 & 50 & \\
\hline $550-60$ & 3 & 50 & \\
\hline $600-60$ & 3 & 50 & \multirow{4}{*}{$>5,27$} \\
\hline $650-60$ & 3 & 50 & \\
\hline $700-60$ & 3 & 50 & \\
\hline $750-60$ & 3 & 50 & \\
\hline $800-60$ & 3 & 50 & $<5,27$ \\
\hline
\end{tabular}

Table S2. Effects of temperature burning to adsorption capacity of VNBC with methylene blue

\begin{tabular}{|c|c|c|c|}
\hline $\begin{array}{c}\text { VNBC } \\
\text { Sample }\end{array}$ & $\mathrm{m}_{\mathrm{O}}$ & $\mathrm{V}_{\text {methylene }}$ & $\begin{array}{c}\text { Adsorption capacity } \\
\text { (mg Methylene/g VNBC) }\end{array}$ \\
\hline $400-60$ & 3 & 50 & \multirow{2}{*}{$<1$} \\
\hline $450-60$ & 3 & 50 & \\
\hline $500-60$ & 3 & 50 & $>1$ \\
\hline $550-60$ & 3 & 50 & \\
\hline $600-60$ & 3 & 50 & \\
\hline $650-60$ & 3 & 50 & \\
\hline $700-60$ & 3 & 50 & \\
\hline $750-60$ & 3 & 50 & \\
\hline $800-60$ & 3 & 50 & \\
\hline
\end{tabular}

Table S3. Effects of time burning to adsorption capacity of VNBC with $\mathrm{KMnO}_{4}$

\begin{tabular}{|c|c|c|c|}
\hline $\begin{array}{c}\text { VNBC } \\
\text { Sample }\end{array}$ & $\mathrm{m}_{\mathrm{O}}$ & $\mathrm{V}_{\mathrm{KMnO} 4}$ & $\begin{array}{c}\text { Adsorption capacity } \\
\left(\mathrm{mg} \mathrm{KMnO}_{4} / \mathrm{g} \text { VNB }\right)\end{array}$ \\
\hline $650-30$ & 3 & 50 & 25,10 \\
\hline $650-60$ & 3 & 50 & 28,89 \\
\hline $650-90$ & 3 & 50 & 33,07 \\
\hline $650-120$ & 3 & 50 & 46,22 \\
\hline $650-150$ & 3 & 50 & 21,05 \\
\hline $650-180$ & 3 & 50 & 14,95 \\
\hline $650-210$ & 3 & 50 & 14,61 \\
\hline
\end{tabular}

Table S4. Effects of time burning to adsorption capacity of VNBC with methylene blue

\begin{tabular}{|c|c|c|c|}
\hline $\begin{array}{c}\text { VNBC } \\
\text { Sample }\end{array}$ & $\mathrm{m}_{\mathrm{O}}$ & $\mathrm{V}_{\text {methylence }}$ & $\begin{array}{c}\text { Adsorption capacity } \\
\text { (mg Methylene/g VNBC) }\end{array}$ \\
\hline $650-30$ & 3 & 50 & 7,48 \\
\hline $650-60$ & 3 & 50 & 10,52 \\
\hline $650-90$ & 3 & 50 & 11,44 \\
\hline $650-120$ & 3 & 50 & 15,4 \\
\hline $650-150$ & 3 & 50 & 7,03 \\
\hline $650-180$ & 3 & 50 & 3,43 \\
\hline $650-210$ & 3 & 50 & 2,00 \\
\hline
\end{tabular}




\section{REFERENCES}

[1] Bawa, K.J.K.S.K.R.A.S. Utilization of byproducts and waste materials from meat, poultry and fish processing industries: a review, J Food Sci Technol, vol. 49, pp. 278-293, 2012.

[2] Omole, A.S.O. D. O. An evaluation of slaughterhouse wastes in south-west Nigeria, American Journal of Environmental Protection, vol. 2, pp. 85-89, 2013.

[3] Edwin Ambani AmesoS.A.B. Charles Owuor Olu, ngah and Tobias Haller, Ethnography of the slaughterhouse: A case of Nanyuki slaughterhouse in Laikipia County, Rift Valley, Kenya, Ameso et al. Pastoralism: Research, Policy and Practice, vol. 7, pp. 32, 2017.

[4] Nasser, M.S.K. Omran, A.M. Faheem A. Sheikh, Hak Yong Kim, Extraction of pure natural hydroxyapatite from the bovine bones bio waste by three different methods, journal of materials processing technology, vol. 209, pp. 34083415, 2009.

[5] Nazia Bano, S.S.J. Hatijah Basri, A.H.N. Sharifah Adzila S. Abu Bakar, Natural Hydroxyapatite Extracted From Bovine Bo, Journal of Science and Technology, vol. 9, pp. 22-28, 2017.

[6] Ammara Kaynata, I.A.M.A.R.K. Ashfaque Pathand, Dr. Health \& environmental impacts of slaughter houses' condition on society - a case study of hyderabad city, $4^{\text {th }}$ International Conference on Energy, Environment and Sustainable Development, 2018.

[7] Al Dufour, J.B. Robert Bos and Victor Gannon, Animal Waste, Water Quality and Human Health, Published by IWA Publishing, London, UK. ISBN: 9781780401232, 2012.

[8] Mirona Palczewska-Komsa, A.W. Anna Stogiera, Dariusz Chlubek, Jadwiga Buczkowska-Radlińska, Barbara Wiszniewska Szczecin, Animals in biomonitoring studies of environmental fluoride pollution, Research review Fluoride, vol. 49, pp. 279-292, 2016.

[9] Shrikant B. P.K. Katole, R.D.P. Environmental pollutants and livestock health: a review, Environmental pollutants and livestock health: a review, vol. 1, pp. 1-13, 2013.

[10] Abbas Rezaee, Hossin-Ali Rangkooy, Ali Khavanin, Ahmad Jonidi-Jafari, Cheshma, Soltani, R.D. Nili-Ahmadabadi, A. Adsorption Properties and Breakthrough Model of Formaldehyde on Bone Char, International Journal of Environmental Science and Development, vol. 2, 2011.

[11] Ikuo Abe, Satoshi Iwasaki, Toshimitsu Tokimoto, Naohito Kawasaki, Takeo Nakamura, Tanada, A.S. Adsorption of fluoride ions onto carbonaceous materials, Journal of Colloid and Interface Science, vol. 275, pp. 35-39, 2004.

[12] Nahum A. Medellin-Castillo, Roberto Leyva-Ramos, Raul Ocampo-Perez, Ramon F. Garcia de la Cruz, Antonio Aragon-Pin, Jose M. Martinez-Rosales, Rosa M. Guerrero-Coronado, a.L. Fuentes-Rubio, Adsorption of Fluoride from Water Solution on Bone Char, Ind. Eng. Chem. Res., vol. 46, pp. 9205-9212, 2007.

[13] Adsorption Kinetics Modeling of A Red Azo Dye Onto Bone Char, Mater thesis, 2013.

[14] Olaniyi, I. Moses, Odoh, S.a.R. Adsorption study of $\mathrm{Cr}$ (VI) and $\mathrm{Pb}$ (II) from aqueous solution using animal charcoal derived from cow bone, Der Chemica Sinica, vol. 3, pp. 648-657, 2012.

[15] Abbas Rezaee, M.R. Ghader Ghanizadeh, Afshin Nili-Ahmadabadi, Adsorption of Escherichia coli Using Bone Char, J. Appl. Sci. Environ. Manage, vol. 15, pp. 57-62, 2011.

[16] Netzer, A. Hughes, D.E. Adsorption of copper, lead and cobalt by activated carbon, Water Res, 18: 927 - 933 , 1984.

[17] Amir Hajialia, G.P.P. Evaluation of Turbidity and Color Removal in Treatment of Wastewater Containing Resistant Pollutants with Ozonation, IERI Procedia, vol. 9, pp. 8 - 12, 2014.

[18] Juan Carlos Moreno, R.G .L. Giraldo, Removal of Mn, Fe, Ni and Cu Ions from Wastewater Using Cow Bone Charcoal, Materials, vol. 3, pp. 452-466, 2010.

[19] Pan, X. Wang, J. Zhang, D. Sorption of cobalt to bone char: Kinetics, competitive sorption and mechanism, Desalination, vol. 249, pp. 609-614, 2009.

[20] Yun-Nen Chen, Li-Yuan Chai, Y.-D. Shu, Study of arsenic (V) adsorption on bone char from aqueous solution, Journal of Hazardous Materials, vol. 160, pp. 168-172, 2008.

[21] Kaseva, M.E. Optimization of regenerated bone char for fluoride removal in drinking water: a case study in Tanzania, Journal of Water and Health, vol. 04, 2006.

[22] Yothin Mutchimadilok, Sunisa Smittakorn, Surat Mongkolnchai-arunya, Durnford, A. D. Defluoridation with Locally Produced Thai Bone Char, Advances in Environmental Chemistry, vol. 9, 2014.

[23] Jha.W.G. Sangeeta Patel, Surface Chemistry and Textural characterization of activated carbon prepared from animal bone chars, using potassium hydroxide $(\mathrm{KOH})$ as an activating agent, Chem Sci Rev Lett, vol. 4, pp. 821-826, 2015.

[24] Sudhakar M. Rao, Venkatarama Reddy, B.V. Lakshmikanth, S. Ambika, N.S. Re-use of fluoride contaminated bone char sludge in concrete, Journal of Hazardous Materials, vol. 166, pp. 751-756, 2009.

[25] Shi-Bao Chen, Yong-Guan Zhu, Yi-Bing Ma, G. McKay, Effect of bone char application on Pb bioavailability in a Pb-contaminated soil, Environmental Pollution, vol. 139, pp. 433-439, 2006.

[26] Xiaohua Wang, N.L. Yunguo Liu, Luhua Jiang, Guangming Zeng, Xiaofei Tan, Shaobo Liu, Zhihong Yin, Sirong Tian, and Jiang Li, Adsorption Removal of 17-Estradiol fromWater by Rice Straw-Derived Biochar with Special Attention to Pyrolysis Temperature and Background Chemistry, Int. J. Environ. Res. Public Health, vol. 14, pp. 1213, 2017.

[27] Agnieszka Sobczak, Z. K. Zbigniew Wzorek, Preparation of hydroxyapatite from animal bones, Acta of 
Bioengineering and Biomechanics, vol. 11, pp. 4, 2009.

[28] Jacobsen, P. Dahi, E. Copenhagen, Denmark, Charcoal packed furnace for low-tech charring of bone, $2^{\text {nd }}$ International Workshop on Fluorosis Prevention and Defluoridation of Water, pp.151-155, 2006.

[29] Faheem A. Sheikh, M.A.K. Javier Macossay, Muneeb A. Muhammad, Travis Cantu, Nasser A. M. Barakat, and Hak Yong Kim, Fabrication of Mineralized Collagen from Bovine Waste Materials by Hydrothermal Method as Promised Biomaterials, J Biomater Tissue Eng., vol.1, pp. 2, 2011.

[30] Nasser A.M. Barakata, Myung Seob Khila, A.M. Omrand, Extraction of pure natural hydroxyapatite from the bovine bones bio waste by three different methods, journal of materials processing technology, vol. 20 9, no. pp. 34083415, 2009.

[31] Lgjapph, Elliott Barrett, P. The Determination of Pore Volume and Area Distributions in Porous Substances. I. Computations from Nitrogen Isotherms, the volume and area distribution in porous substances, vol. 73, $2015,1951$.

[32] Heael. Stephebnr Unauerp, Adsorption of Gases in Multimolecular Layers, contributiofrno $m$ the bureauof chemistrayn d sons and georgew ashingtounn iversi, pp. 60, 1938.

[33] Yanyan Chen, C.Z. Maria Mastalerz, Suyun Hu, Carley Gasaway and Xiaowan Tao, Applications of Micro-Fourier Transform Infrared Spectroscopy (FTIR) in the Geological Sciences_A Review, Int. J. Mol. Sci., vol. 16, pp. 3022330250, 2015. 